Article

\title{
Experimental Study to Design Warm Mix Asphalts and Recycled Warm Mix Asphalts Using Natural Zeolite as Additive for Sustainable Pavements
}

\author{
Elsa Sanchez-Alonso *, Gonzalo Valdes-Vidal and Alejandra Calabi-Floody \\ Department of Civil Engineering, Universidad de La Frontera, Francisco Salazar street 01145, \\ Temuco 4811230, Chile; gonzalo.valdes@ufrontera.cl (G.V.-V.); alejandra.calabi@ufrontera.cl (A.C.-F.) \\ * Correspondence: elsa.sanchez@ufrontera.cl
}

Received: 20 November 2019; Accepted: 19 January 2020; Published: 29 January 2020

\begin{abstract}
There are currently various technologies for the manufacture of warm mix asphalts (WMA). This paper presents the possibility of using a natural zeolite to manufacture WMA as an alternative to existing synthetic products for the manufacture of this type of mixture. Moreover, the possibility of manufacturing WMA with the addition of recycled asphalt pavement (RAP) using natural zeolite as the basis of a warm mix technology was evaluated. Firstly, asphalt mixtures were manufactured at three different temperatures $\left(145^{\circ} \mathrm{C}, 135^{\circ} \mathrm{C}\right.$, and $\left.125^{\circ} \mathrm{C}\right)$ with different percentages of natural zeolite to determine the temperature and the optimum content for the manufacture of WMA. Then, the zeolite moisture content and its release over time were determined at different temperatures, and its distribution in the binder was checked at different concentrations by scanning electron microscopy and fluorescence. Next, with the optimum zeolite content, the addition of RAP between $10-30 \%$ in the WMA at the same three manufacturing temperatures was evaluated. Two types of compaction were used: the impact and gyratory compactions. The Marshall parameters were evaluated for all the designed mixtures. The results indicated that the manufacture of WMA with the addition of natural zeolite is feasible, and depending on the required mixing temperature, recycled WMA with different percentages of RAP can be obtained.
\end{abstract}

Keywords: warm mix asphalt; natural zeolite; RAP; recycled warm mix asphalt; temperature; air void

\section{Introduction}

The pavement industry currently faces a double dilemma: on the one hand, the demand for environmentally friendly asphalt materials has increased, and on the other hand, the cost of raw materials has risen [1]. Therefore, the industry has worked on the drop-in manufacturing temperatures through different technologies that have emerged since 1996, when the European Union (EU) began to legislate with respect to emissions produced by in the asphalt industry [2]. France is the only EU country where the production of warm mix asphalts (WMA) is above $10 \%$ of its production. However, in other European countries, its use is limited to laboratory tests and test sections [2]. By contrast, these technologies were used to manufacture $32 \%$ of the total mixes manufactured in the US in 2014 [3].

There are several studies on the use of different techniques to manufacture WMA. For example, Sengoz et al. [4] evaluated different WMA technologies (zeolites, an organic additive and another chemical), to determine the stability in storage, the mixing and compaction temperatures in terms of the optimum of additive, as well as the rheological properties to check their performance. According to the results obtained, the mixing temperatures were reduced between $6{ }^{\circ} \mathrm{C}$ to $13{ }^{\circ} \mathrm{C}$ and the compaction between $6{ }^{\circ} \mathrm{C}$ to $10^{\circ} \mathrm{C}$ depending on the type of additives used, being $3 \% \mathrm{~s} / \mathrm{b}$ the optimum for the organic and chemical additives and between $5-6 \% \mathrm{~s} / \mathrm{b}$ for zeolites to be able to use them in conditions of heavy traffic and high temperatures. 
Sanchez-Alonso et al. [5] evaluated the ease of compaction, water sensitivity and stiffness of WMA with waxes, zeolites and tensoactives at different manufacturing temperatures. The results showed that all additives improved the workability of the asphalt mixtures manufactured compared to the reference hot asphalt mixture (HMA). The additivated asphalt mixtures had better water sensitivity results compared than the reference mixture at the same manufacture temperature. In all the asphalt mixtures manufactured (reference and modified), the stiffness moduli were reduced, but this reduction was less in the case of warm asphalt mixtures. In 2013, Sanchez-Alonso et al. [6] continued their study of WMA behavior, evaluating the rutting and fatigue behavior of the same WMA. All the WMA studied were more deformable than HMA, but the asphalt mixtures with waxes and zeolite additives manufactured at $140{ }^{\circ} \mathrm{C}$ showed similar fatigue life to HMA.

Woszuk and Franus [7] evaluated the mechanical properties of two different zeolites: a synthetic and a natural one, which had $28 \%$ and $17 \%$ water in their structure, respectively. Three compaction temperatures in the design of the mixtures $\left(145^{\circ} \mathrm{C}, 130{ }^{\circ} \mathrm{C}\right.$, and $\left.115^{\circ} \mathrm{C}\right)$ were used, obtaining a natural zeolite optimum of $1 \% \mathrm{w} / \mathrm{m}$ and $0.5 \% \mathrm{w} / \mathrm{m}$ for the synthetic zeolite. The results of water sensitivity and plastic deformations showed a good performance with both zeolites according to Polish specifications. Topal et al. [8] evaluated the Marshall stability properties, stiffness modulus, and indirect tensile fatigue of asphalt mixtures made with natural and synthetic zeolites. According to the data shown by the authors, a slight decrease in the amount of binder is required compared to the conventional asphalt mixtures, which would mean an initial cost saving. The use of both zeolites increased the stiffness of the mixture. However, comparing the results of fatigue resistance and permanent deformation, the results were slightly better with the synthetic zeolite. Wu and Li [9] evaluated the effect of the curing time (two weeks, one and two months) for WMA manufactured with synthetic zeolite. The properties evaluated were dynamic modulus, rutting, resistance to moisture damage, and fatigue behavior. The results showed that the WMA properties improved with the curing time, probably due to losing of water contained in the mixture, unlike the HMA, the properties of which were not affected and remaining practically constant over the time.

On the other hand, the use of different materials that were previously thrown away makes it possible to reduce the demand of raw materials by reducing the environmental impact generated by their production and the associated energy saving [10], resulting in lower costs for companies. These materials include steel slag, shingles, coal ash, and recycled asphalt pavement (RAP) [11]. The use of RAP offers a second life to the aggregates and binder that they have in their composition, decreasing the high costs associated with oil and the extraction of raw materials [12]. When combining RAP technology with WMA techniques in addition to saving on raw materials, there would be a decrease in $\mathrm{CO}_{2}$ emissions, which results in a more environmentally friendly mixture [13,14], obtaining mechanical properties of WMA with RAP similar to the conventional HMA [15].

Using Superpave ${ }^{\circledR}$ methodology, Xiao et al. [16] presented a study on the volumetric properties of asphalt mixtures manufactured with two different technologies (Evotherm ${ }^{\circledR}$ and foamed bitumen), with three different types of binders (two PG64-22 and one PG58-28) and, two RAP of different origin, using them in four different percentages varying between $20 \%$ and $50 \%$. According to the results, the increase of RAP content increased the binder viscosity regardless of the type of binder, origin of the RAP or test temperature. The increase of \%RAP did not affect the optimum binder content regardless of the origin and type of binder used. The percentage of air voids was affected by the type of binder and the WMA technology used. The mineral aggregate voids in WMA were reduced by increasing the $\%$ RAP regardless of the binder origin. The filler-bitumen relationship was affected by the RAP content and not by the WMA technology used.

Zhao et al. [17] evaluated the properties of water sensitivity, resistance to plastic deformation, and fatigue of two different WMA technologies (Evotherm ${ }^{\circledR}$ additive and foaming technique) using several percentages of RAP, between 15 and $40 \%$. The WMAs showed lower resistance to plastic deformations than their HMA counterparts, regardless of the WMA technology used, \%RAP or pavement layer evaluated. The addition of RAP improved the results of WMAs and HMAs, regardless of the WMA 
technology or the pavement layer. WMAs with lower RAP contents presented better results than WMAs with high \%RAP. The addition of RAP increased the fatigue resistance of WMAs and decreased it in HMAs by up to $30 \%$ RAP. The addition of RAP to a maximum of $30 \%$ can be an alternative to reduce the moisture susceptibility of the WMAs without taking into account the WMA technology used or the pavement layer.

Oner and Sengoz [18] evaluated the use of different WMA technologies with the addition of RAP, at a manufacturing $\left(147-152^{\circ} \mathrm{C}\right)$ and compaction $\left(135-140{ }^{\circ} \mathrm{C}\right)$ temperatures, and presented a cost-benefit evaluation of these techniques. To carry out the study, they used an organic additive, a chemical additive, and a last one containing water in the proportions recommended by the manufacturers. According to the results, the RAP optimum obtained for each technique was $30 \%, 10 \%$, and $20 \%$, respectively. With respect to the cost-benefit analysis that they carried out, it was concluded that a cost saving to WMA compared with the conventional mixture was obtained using both WMA and WMA + RAP technologies. According to the data shown, the greatest saving occurred using WMA + RAP, between $8-25 \%$ compared with respect to HMA, depending on the chosen technique.

As noted above, there are many WMA techniques that have been developed in recent times. They are based on the use of emulsifying chemical additives, organic additives to lower the viscosity of asphalt binders, or the use of synthetic additives that generates foaming processes. However, the study of WMA with the use of natural additives, such as natural zeolite, has not been sufficiently addressed both in its design phase and its mechanical properties, as well as the influence of the compaction process. Therefore, this paper presents the possibility of using a natural zeolite to produce WMA mixtures as an alternative to existing synthetic products for the manufacture of this these types of mixtures. In turn, the possibility of manufacturing WMA mixtures with the addition of RAP using natural zeolite as the basis of WMA technology is evaluated.

\section{Materials and Methods}

\subsection{Materials}

A conventional asphalt binder is used in this research. Its characterization according to Chilean specifications is shown in Table 1.

Table 1. Properties of conventional asphalt binder.

\begin{tabular}{ccc}
\hline Tests & CA-24 & Criteria \\
\hline Absolute Viscosity at $60^{\circ} \mathrm{C}, 300 \mathrm{~mm} \mathrm{Hg}(\mathrm{P})$ & 3077 & $\left({ }^{*}\right)$ \\
Ductility at $25^{\circ} \mathrm{C},(\mathrm{cm})$ & $>150$ & Min 100 \\
Oliensis Spot Test, $(\%$ xylene $)$ & $<25$ & Max 25 \\
Cleveland Open Cup Flash Point, $\left({ }^{\circ} \mathrm{C}\right)$ & 332 & Min 232 \\
Softening Point R\&B, $\left({ }^{\circ} \mathrm{C}\right)$ & 51 & To be reported \\
Penetration Index & -0.7 & $-1.5 \mathrm{a}+1.0$ \\
\hline RTFOT & & \\
\hline Mass Loss, $(\%)$. & 0.0 & Max 0.8 \\
Absolute Viscosity at $60^{\circ} \mathrm{C}, 300 \mathrm{~mm} \mathrm{Hg}(\mathrm{P})$ & 7475 & To be reported \\
Ductility at $25^{\circ} \mathrm{C}, 5 \mathrm{~cm} / \mathrm{min}$ & $>150$ & Min 100 \\
Durability Index & 2.4 & Max 3.5 \\
\hline
\end{tabular}

$\left.{ }^{*}\right)$ : Min 2400 for CA-24.

The fluvial aggregates composed mainly of dolomite, basalt, dacite, andesite, rhyolite, sandstone, quartz, and quartzite were characterized for their use in asphalt mixtures according to the Chilean standards (Table 2). 
Table 2. Properties of aggregates.

\begin{tabular}{ccccc}
\hline Type of Aggregate & \multicolumn{1}{c}{ Tests } & Results & Criteria \\
\hline \multirow{4}{*}{ Coarse } & Los Angeles Abrasion Loss & $(\%)$ & 18.4 & $<25\left(^{*}\right)-35 \%$ \\
& Crushed Particles & $(\%)$ & 97.3 & $>90\left(^{*}\right)-70 \%$ \\
& Flakiness Index & $(\%)$ & 0.1 & $<10\left(^{*}\right)-15 \%$ \\
& Specific Gravity & $\left(\mathrm{kg} / \mathrm{m}^{3}\right)$ & 2661 & - \\
& Absorption & $(\%)$ & 1.54 & - \\
\hline \multirow{2}{*}{ Fine } & Plasticity index & & Non plastic & Non plastic \\
& Riedel-Weber adhesion & & $0-9$ & Min. 0-5 \\
& Specific gravity & $\left(\mathrm{kg} / \mathrm{m}^{3}\right)$ & 2629 & - \\
& Absorption & $(\%)$ & 1.09 & - \\
\hline
\end{tabular}

$\left.{ }^{*}\right)$ Surface layer.

The natural zeolite used in this research is a clinoptilolite and was acquired from the Maule Region in Chile. Due to its open and porous structure, this material could maintain water or other type of chemical elements inside of its structure. This natural zeolite contains water, which will be released if it is heated at temperatures beyond $100{ }^{\circ} \mathrm{C}$, provoking a micro-foaming into the asphalt binder. Therefore, this natural additive could be used to manufacture warm asphalt mixtures. The characterization of the natural zeolite is shown in Table 3.

Table 3. Properties of the natural zeolite.

\begin{tabular}{|c|c|}
\hline & Identification of Mineral \\
\hline Description & Clinoptilolite-natural zeolite \\
\hline Chemical name & Calcium magnesium aluminosilicates hydrated \\
\hline \multirow[t]{2}{*}{ Grain size } & $0-0.173 \mathrm{~mm}$ \\
\hline & Mineralogical Characteristics \\
\hline Main zeolitic component & Clinoptilolite \\
\hline Other components & Plagioclase, Smectite and Quartz \\
\hline \multirow[t]{2}{*}{ Color } & Ivory \\
\hline & Physicochemical Characteristics \\
\hline Chemical composition (\%) & $\begin{array}{c}\mathrm{SiO}_{2}: 64.19 ; \mathrm{TiO}_{2}: 0.51 ; \mathrm{Al}_{2} \mathrm{O}_{3}: 11.65 ; \mathrm{Fe}_{2} \mathrm{O}_{3}: 2.53 ; \mathrm{MnO}: 0.03 ; \\
\mathrm{MgO}: 0.66 ; \mathrm{CaO}: 3.42 ; \mathrm{Na}_{2} \mathrm{O}: 0.75 ; \mathrm{K}_{2} \mathrm{O}: 1.60 ; \mathrm{P}_{2} \mathrm{O}_{5}: 0.03 ; \mathrm{PxC}: \\
14.64\end{array}$ \\
\hline Cation exchange capacity (cec) & 86.82 a $112.88 \mathrm{cmol} / \mathrm{kg}$ \\
\hline Specific surface (Bet method) & 446 a $480 \mathrm{~m}^{2} / \mathrm{g}$ \\
\hline Thermal stability & $<450{ }^{\circ} \mathrm{C}$ \\
\hline Chemical stability & 8.9 \\
\hline Density & $0.661 \mathrm{~g} / \mathrm{cm}^{3}$ \\
\hline
\end{tabular}

The RAP used came from milling works on Route 5, in La Araucania Region (Chile). RAP was separated in two fractions: $0 / 5 \mathrm{~mm}$ and $5 / 20 \mathrm{~mm}$. It was characterized to know its gradation and bitumen content (Table 4) as well as and the properties of bitumen recovered (Table 5). 
Table 4. RAP gradation and bitumen content (after extraction).

\begin{tabular}{ccc}
\hline RAP Fraction (mm) & $0 / 5$ & $5 / 20$ \\
\hline Bitumen Content (\% by Weight of Mix) & 7.5 & 3.3 \\
\hline Sieve Size (mm) & Gradation (\% Passing) & Gradation (\% Passing) \\
\hline 20 & 100 & 100 \\
12.5 & 100 & 73 \\
10 & 100 & 56 \\
5 & 100 & 29 \\
2.5 & 70 & 18 \\
0.63 & 35 & 11 \\
0.315 & 25 & 8 \\
0.16 & 19 & 5 \\
0.08 & 15 & 4 \\
\hline
\end{tabular}

Table 5. Characteristics of binder recovered from the RAP.

\begin{tabular}{cc}
\hline Tests & Results \\
\hline Penetration at $25{ }^{\circ} \mathrm{C}, 100 \mathrm{~g} .5 \mathrm{~s} .(0.1 \mathrm{~mm})$ & 10 \\
Fraas Breaking Point $\left({ }^{\circ} \mathrm{C}\right)$ & +3 \\
Softening Point $\mathrm{R} \& \mathrm{~B}\left({ }^{\circ} \mathrm{C}\right)$ & 55.6 \\
Brookfield Viscosity at $60{ }^{\circ} \mathrm{C}(\mathrm{Pa} \mathrm{s})$ & 30.883 \\
\hline
\end{tabular}

\subsection{Mix Design}

A semi-dense type IV-A-12 gradation with a maximum aggregate size of $12.5 \mathrm{~mm}$ was selected. The IV-A-12 particles were classified by size and adjusted to the grading envelope as shown in Figure 1.

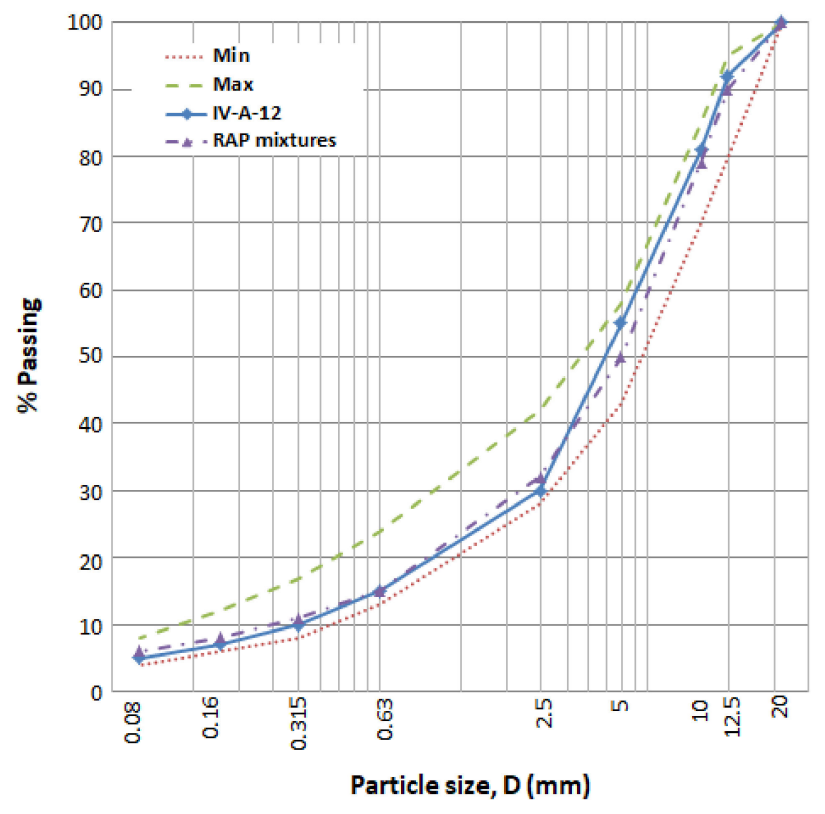

Figure 1. IV-A-12 aggregate gradation.

The optimum asphalt binder content was obtained by the Marshall method and the analysis of air voids in a reference mix ( $\mathrm{R} \mathrm{mix}$ ) manufactured at $155^{\circ} \mathrm{C}$, leading to $5.4 \%$ weight of aggregates. This optimal optimum binder content was used in the manufacture of all the mixtures included in this paper. 
Three manufacturing temperatures were studied: $145^{\circ} \mathrm{C}, 135^{\circ} \mathrm{C}$, and $125^{\circ} \mathrm{C}$. Four percentages of natural zeolite were evaluated $(0.3,0.6,0.9$, and $1.2 \%)$ to obtain the optimum amount of additive to achieve the lowest manufacturing temperature of asphalt mixtures.

With the optimum content of natural zeolite, three percentages of RAP were analyzed $(10 \%, 20 \%$, and $30 \%$ ) to obtain recycled warm mixtures asphalts (RWMA). The content of raw binder for each RAP mixture was calculated, considering that $50 \%$ of the RAP binder contributes to the mixture and using the Federal Highway Administration method [19]. To obtain the manufactured temperatures in RWMA, the raw aggregates were overheated, taking into account the moisture content of RAP [20]. In Table 6, the characteristics of the RWMA studied are shown.

Table 6. Characteristics of Recycled Warm Mixture Asphalt studied.

\begin{tabular}{ccccccc}
\hline Mixture & \multicolumn{2}{c}{ Binder Content (\%) } & \multicolumn{2}{c}{ Temperatures $\left({ }^{\circ} \mathbf{C}\right)$} \\
\hline Raw Aggregate & RAP & CA-24 & $\begin{array}{c}\text { RAP } \\
\text { Contribution }\end{array}$ & $\begin{array}{c}\text { Raw } \\
\text { Aggregates }\end{array}$ & RAP & Mixture \\
\hline 100 & - & 5.4 & - & 155 & - & 155 \\
90 & 10 & 5.19 & 0.21 & 162 & 15 & 145 \\
90 & 10 & 5.19 & 0.21 & 152 & 15 & 135 \\
90 & 10 & 5.19 & 0.21 & 142 & 15 & 125 \\
80 & 20 & 4.98 & 0.43 & 180 & 15 & 145 \\
80 & 20 & 4.98 & 0.43 & 169 & 15 & 135 \\
80 & 20 & 4.98 & 0.43 & 157 & 15 & 125 \\
70 & 30 & 4.77 & 0.54 & 202 & 15 & 145 \\
70 & 30 & 4.77 & 0.54 & 190 & 15 & 135 \\
70 & 30 & 4.77 & 0.54 & 178 & 15 & 125 \\
\hline
\end{tabular}

\subsection{Methodology}

First, the moisture content of the natural zeolite was determined. For this, the samples were dried in an oven at $110 \pm 5^{\circ} \mathrm{C}$ until constant mass, obtaining the moisture content of the zeolite by means of the loss of mass of the sample. In addition, a test was carried out to determine the process of releasing the water contained in its structure over time, and compared with a commercial synthetic zeolite used for the manufacture of WMA. This test was made at temperatures of $155^{\circ} \mathrm{C}, 145^{\circ} \mathrm{C}$, and $135^{\circ} \mathrm{C}$, and were measured every $5 \mathrm{~min}$ up to $90 \mathrm{~min}$, the average period of time estimated for the manufacture and the laying process of an asphalt mixture. On the other hand, the dispersion of the natural zeolite in the asphalt binder was verified by scanning electron microscopy (SEM) and fluorescence images, using different amounts of natural zeolite, $1 \%, 5 \%$, and $10 \%$, by weight of the binder.

For the compaction of the different asphalt mixtures manufactured, the impact and gyratory compactions were used. In the case of impact compaction, the specimens were compacted to 75 blows per face. In the case of the gyratory compactor, a vertical pressure of $600 \mathrm{kPa}$ was applied with a compaction angle of $1.16^{\circ}$ and a speed of $30 \mathrm{rpm}$. The number of cycles was 100 for each mixture and the diameter of the mold used was $100 \mathrm{~mm}$. To the impact and gyratory specimens, the Marshall parameters such as density, stability, flow, and the air and mineral aggregate voids were determined. Chile only has mix design specifications for asphalt mixtures compacted by impact, but these values were used as a guide to analyze the results obtained with the gyratory compactor.

\section{Analysis of Results}

The moisture content was calculated for both zeolites. The average of moisture content obtained in the natural zeolite was $12.6 \%$ in mass, a percentage lower than the water content of synthetic zeolite, which was around $20 \%$ in mass. However, as shown in Figure 2, the water release curves at the different temperatures evaluated indicate that the natural zeolite released higher water content during the time of manufacturing and laying of the asphalt mixtures, unlike the synthetic zeolite, which did it for a longer time. This could be due to the difference of chemical elements that the zeolites may have 
in their structure. The composition of synthetic zeolite is purer (less variability) than natural zeolite (generated by different geological processes). However, the compounds used in its synthesis could have more polar elements than natural zeolite, generating more polar structure and therefore greater attraction to water (formation of chemical bonds like Van der Waals or hydrogen bonds), requiring more time applying heat to release all the water contained. According to the results shown, the use of natural zeolite as substitute for synthetic zeolites seems feasible.

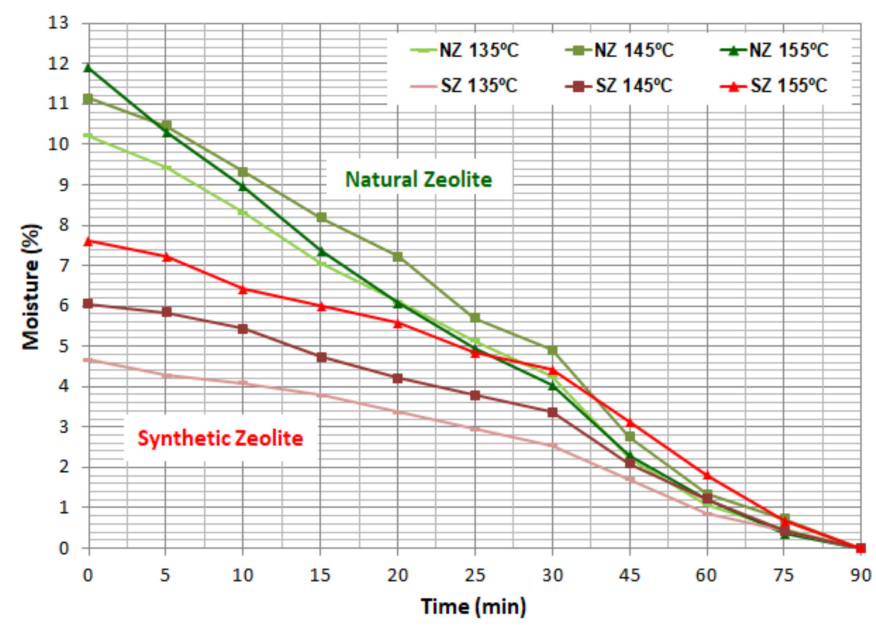

Figure 2. Water release of the natural zeolite vs. synthetic zeolite at different temperatures.

The analysis of the natural zeolite dispersion in the binder shown in Figure 3 demonstrated a good dispersion within the binder at the three proportions studied, which would help to achieve a greater optimization of the foaming effect in the asphalt mixtures. However, at the $10 \%$ concentration of natural zeolite on binder, zeolite clusters began to appear, so higher concentrations of this additive would not be recommended since the distribution of the additive would not be homogeneous and could affect the quality of the mixture.

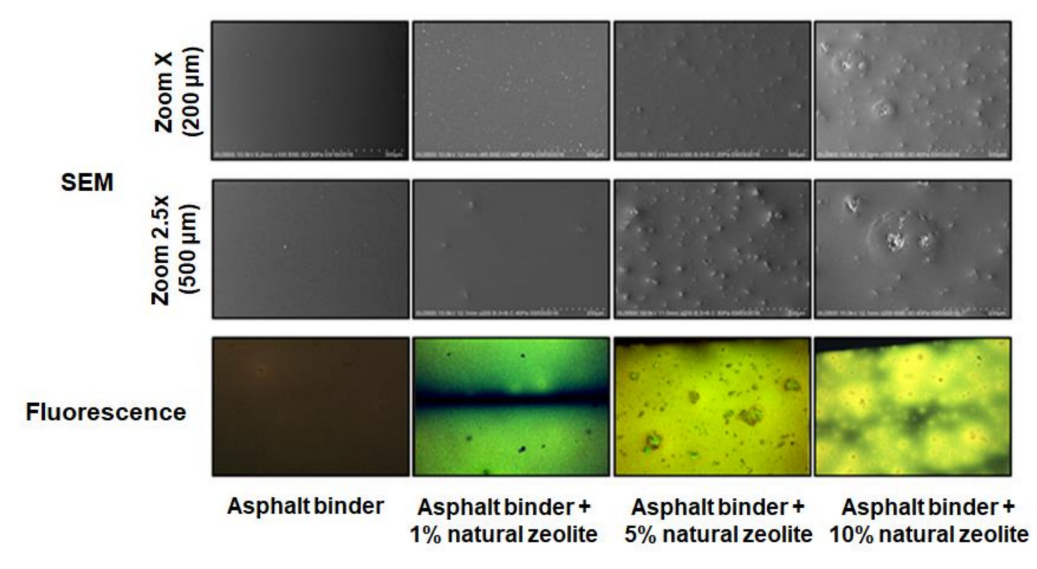

Figure 3. Dispersion of natural zeolite in asphalt binder.

The results of the Marshall parameters of the WMA are presented in Figures 4 and 5. According to the results shown, when the manufacturing temperature is reduced, there was a decrease in the density of the asphalt mixtures, although the addition of zeolite seemed to mitigate this decrease in density, as can be seen with the results obtained at $135{ }^{\circ} \mathrm{C}$ (Figure $4 \mathrm{~A} \mathrm{left}$ ). On the other hand, the density values obtained with the gyratory specimens did not present significant differences in the density regardless of the manufacturing temperature and the amount of zeolite used, although higher densities were obtained compared to the impact specimens (Figure $4 \mathrm{~A}$ right). 

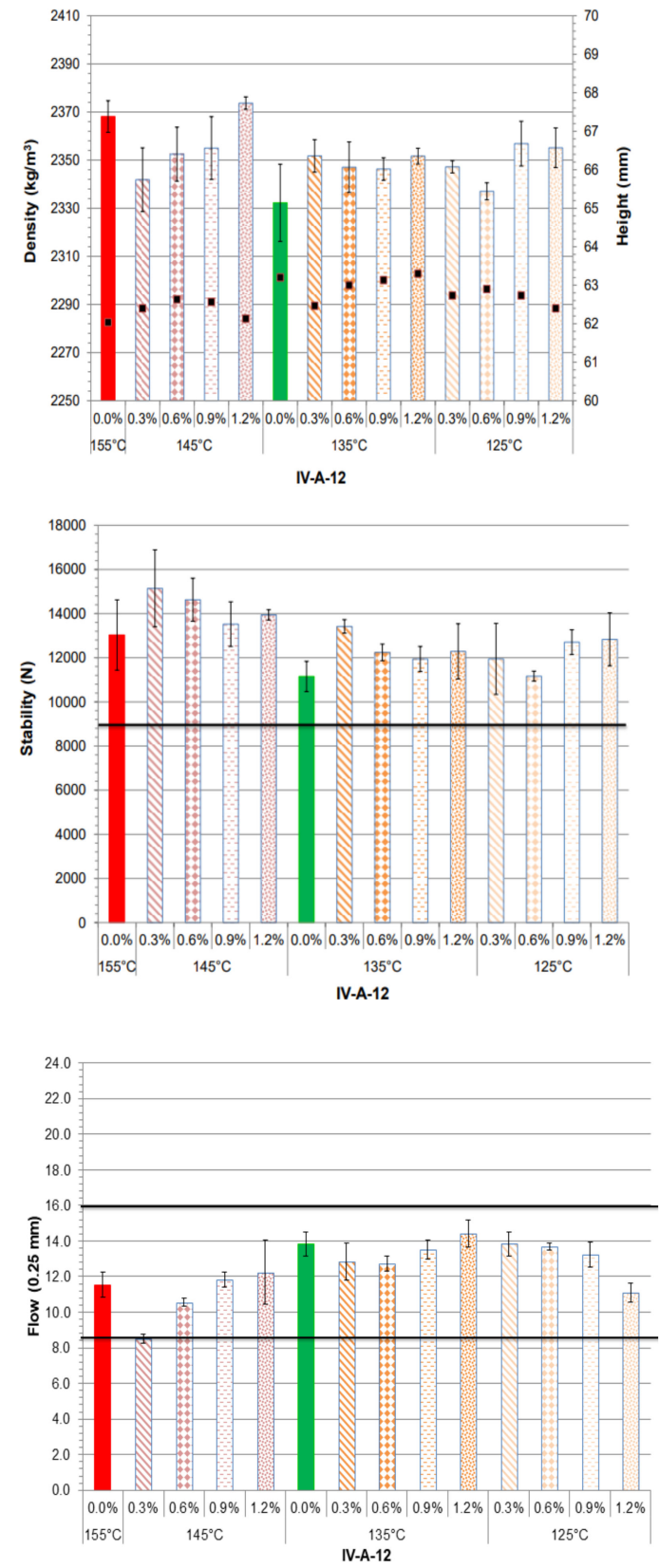

(A)
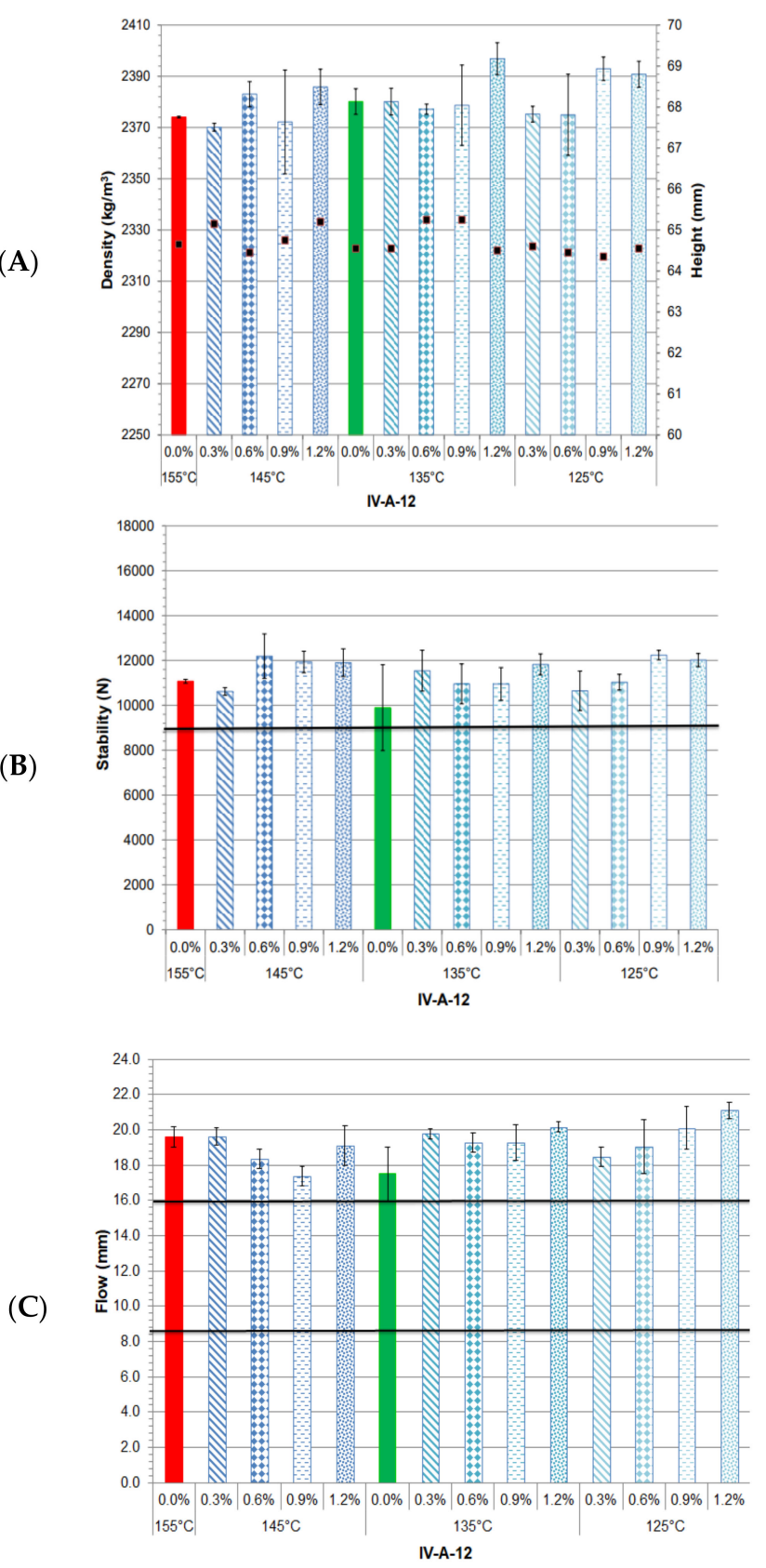

Figure 4. Results of Marshall parameters for WMA specimens compacted by impact (left) and by gyratory compactor (right): (A) Density, (B) Stability, (C) Flow.

All WMA fulfilled the stability specifications required by Chilean standards (9000 N), regardless of manufacturing temperature and the amount of natural zeolites used (Figure 4B). The mixtures manufactured at $135{ }^{\circ} \mathrm{C}$ and $125^{\circ} \mathrm{C}$ obtained stability values similar to the reference mixture. If it compares a reference mixture manufactured at $135^{\circ} \mathrm{C}$ against the WMA with the different percentages of additives, it can see the influence of the addition of natural zeolite, improving the stability values obtained. On the other hand, although the gyratory specimens complied with the minimum value required by the standards, they obtained lower values than the impact specimens (Figure $4 \mathrm{~B}$ right). This may be due to the kneading effect produced by the gyratory compaction which causes the aggregates to settle within the structure in a more efficiently way. 


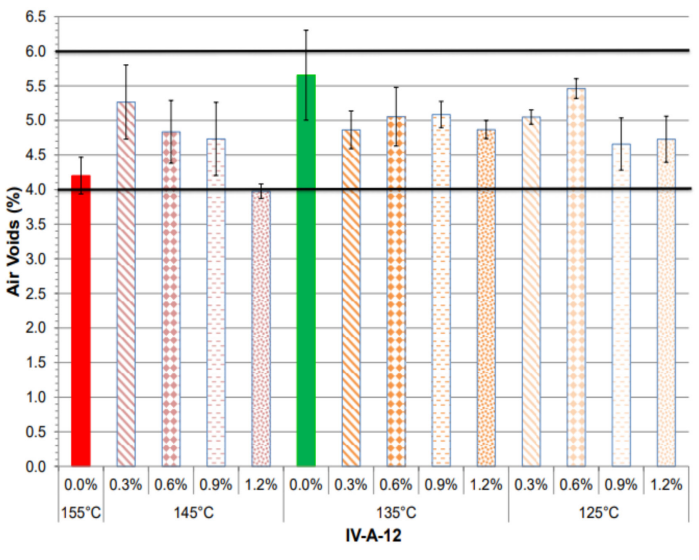

(A)
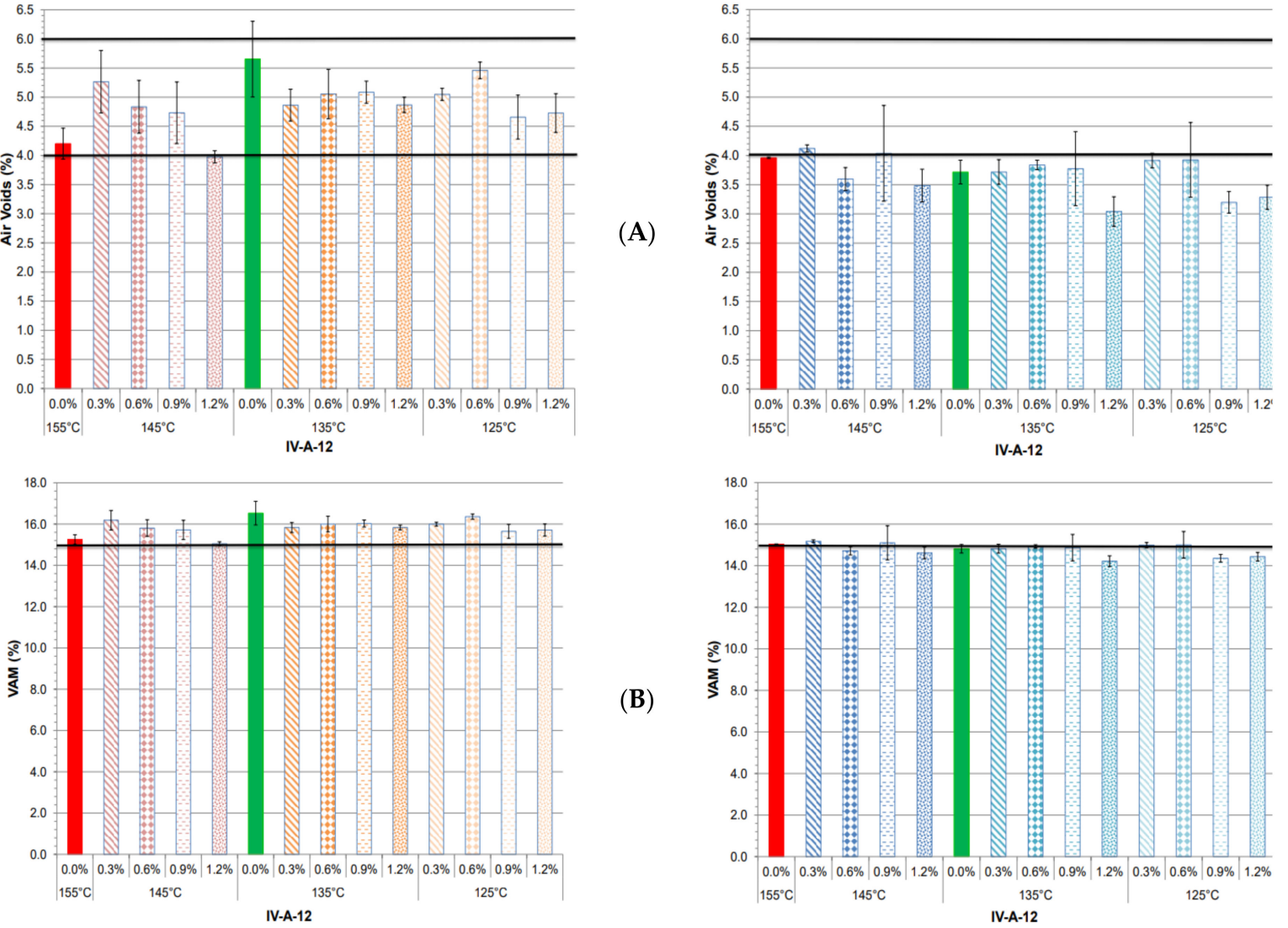

Figure 5. Results of Marshall parameters for WMA specimens compacted by impact (left) and by gyratory compactor (right): (A) Air voids, (B) VAM.

Regarding the flow results, all WMA compacted by impact obtained values within the requirements by the Chilean standards (9-16 in $0.25 \mathrm{~mm}$ units). However, the gyratory specimens obtained values higher than the upper limit indicated in the standards and no significant trend was observed with the reduction of the temperature or the variation of the additive content (Figure 4C).

All WMA compacted by impact complied with the values established in the Chilean standards, both in percentage of air and mineral aggregate voids (Figure 5A,B left). On the other hand, the gyratory WMA did not show a clear tendency in the variation of the percentage of air and mineral aggregate voids due to the increased of the percentage of natural zeolite used or by the manufacturing temperature (Figure $4 \mathrm{~A}, \mathrm{~B}$ right). Although most of the mixtures were below the limit of the percentage of air and mineral aggregate voids allowed, this may be due to the over-compacting of the asphalt mixtures by an excess of the number of cycles during compaction.

Although all the WMA complied with the Marshall parameters indicated in the standards, not all the asphalt mixtures achieved a good coating of the aggregates. The $30^{\circ} \mathrm{C}$ reduction in the manufacture of the asphalt mixtures caused a lack of aggregates' coating with any of the proportions of natural zeolite (Figure 6A). So, this could cause problems with the water, which could significantly affect the structure of the pavement and/or lead to significant deteriorations. The WMA at $145^{\circ} \mathrm{C}$ and $135^{\circ} \mathrm{C}$ and all the amounts of natural zeolite used were possible to achieve a good aggregate coating (Figure 6B,C). Based on these results and in the search for a greater reduction in costs and energy, the optimum WMA would be manufactured at $135{ }^{\circ} \mathrm{C}$ with $0.3 \%$ and $0.6 \%$ of zeolite. 


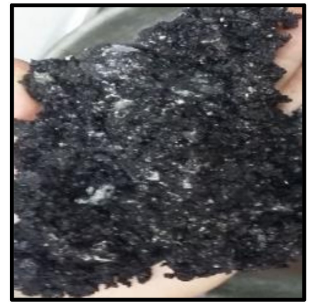

(A)

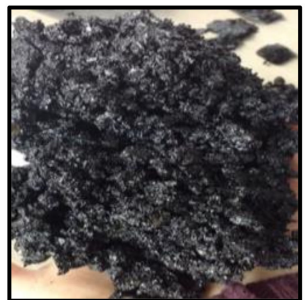

(B)

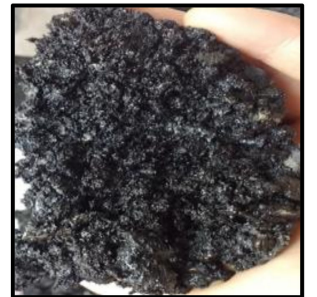

(C)

Figure 6. Coating of aggregates of WMA with $0.3 \%$ of natural zeolite at: (A) $125^{\circ} \mathrm{C}$, (B) $135{ }^{\circ} \mathrm{C}$, (C) $145^{\circ} \mathrm{C}$.

In the case of recycled WMAs (RWMA), they were manufactured using $0.6 \%$ zeolite in the asphalt mixture to facilitate the foaming of the binder provided by the RAP. In Figures 7 and 8, the results of the Marshall parameters are shown. The density results obtained showed that as the RAP content in the mixture increased, the mixtures became denser for the same manufacturing temperature (Figure 7A left). Similarly to what occurred with the WMAs, the density of the gyratory specimens was higher than the impact ones (Figure 7A right), probably due to the kneading effect produced by this type of compaction.

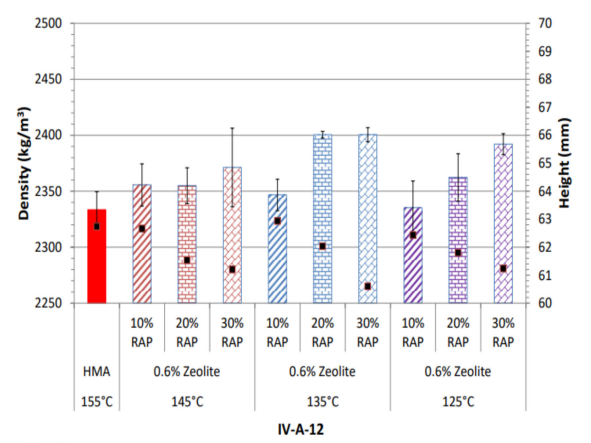

(A)
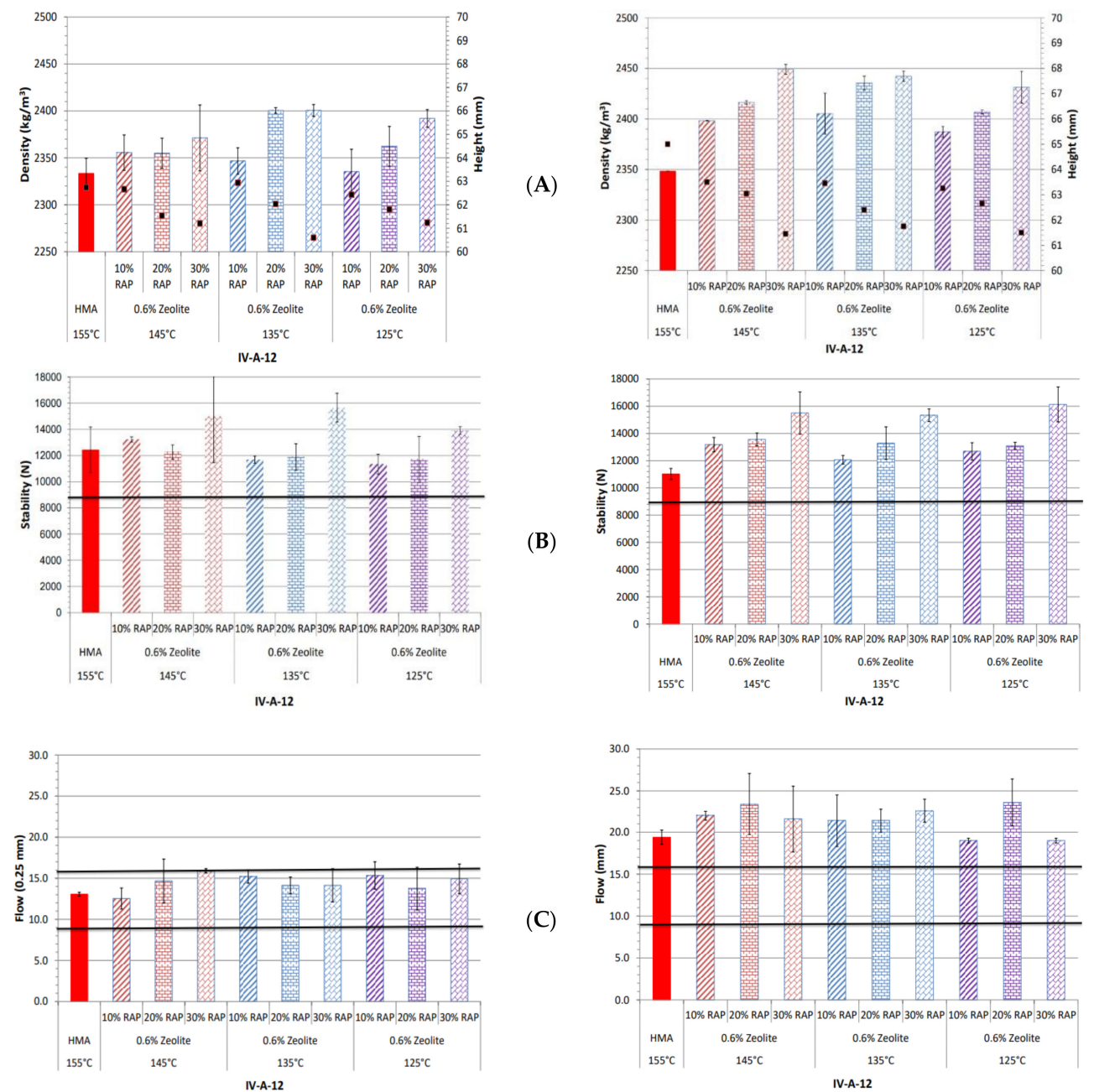

Figure 7. Results of Marshall parameters for RWMA specimens compacted by impact (left) and by gyratory compactor (right): (A) Density, (B) Stability, (C) Flow. 


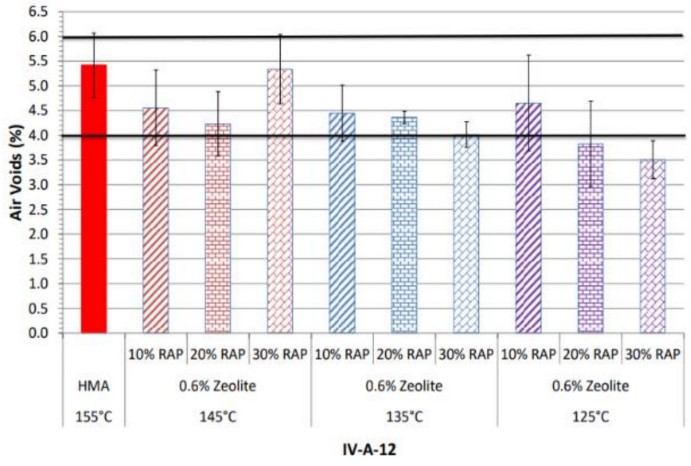

(A)
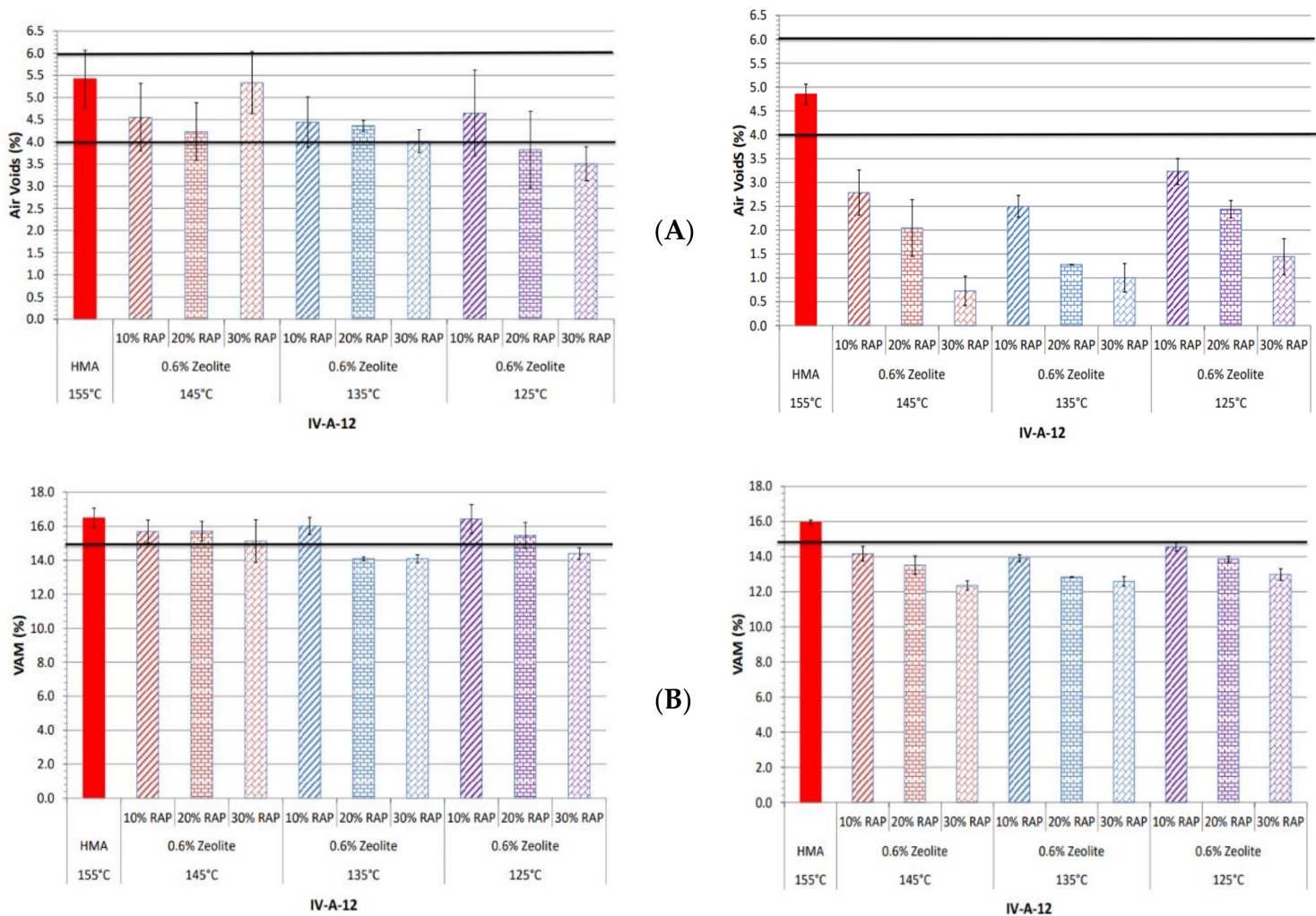

Figure 8. Results of Marshall parameters for RWMA specimens compacted by impact (left) and by gyratory compactor (right): (A) Air voids, (B) VAM.

Concerning the stability of the recycled warm asphalt mixtures, for both compact and gyratory specimens, they complied with the minimum established in the Chilean standards (Figure 7B). With the results of gyratory specimens, for the same temperature, the stability increased with the RAP content in the asphalt mixture. However, for the same amount of RAP, the stability remained almost constant when the manufacturing temperature was changed.

In the case of flow, the asphalt mixtures compacted by impact complied with Chilean requirements. However, the gyratory asphalt mixtures exceeded the upper limit (Figure 7C). With both types of compaction, the influence of the manufacturing temperature or the RAP content had not clear trend in the results. With respect to the content of air and mineral aggregate voids obtained in the impact compactor, all the mixtures complied with the requirements of the standard, except for mixtures with $20 \%$ and $30 \%$ RAP at $125^{\circ} \mathrm{C}$ and $30 \%$ RAP at $135^{\circ} \mathrm{C}$ (Figure $8 \mathrm{~A}, \mathrm{~B}$ left). However, analogous to the results of WMAs, the gyratory compaction of the RWMA produced values of both types of voids quite below that required by the standard (Figure 8A,B right).

According to the results obtained and seeking to optimize the different variables evaluated, three types of RWMA could be obtained: one where the decrease in temperature was maximized to the detriment of RAP (manufacturing temperature at $125^{\circ} \mathrm{C}$ and $10 \%$ RAP), another one in which the amount of RAP is was maximized without lowering the temperature much (manufacturing temperature at $145^{\circ} \mathrm{C}$ and $30 \% \mathrm{RAP}$ ), and a third mixture where both variables were optimized (manufacturing temperature at $135^{\circ} \mathrm{C}$ and $\left.20 \% \mathrm{RAP}\right)$.

\section{Conclusions}

The addition of the natural zeolite to the asphalt mixture generates a micro-foaming when it comes into contact with the asphalt binder, which allows for a better coating of the aggregates in the mixture when the temperature is reduced. 
Although all WMAs at the three temperatures and the four natural zeolite contents complied with the parameters of the Marshall design, the WMAs manufactured at $125^{\circ} \mathrm{C}$ had difficulties in the process of coating the aggregates because the workability of the asphalt mixture decreased with respect to the manufacture process at $145^{\circ} \mathrm{C}$ and $135^{\circ} \mathrm{C}$. Therefore, it is not recommended that the manufacturing and compaction temperatures be reduced below $20^{\circ} \mathrm{C}$ compared to the HMA.

According to the results obtained, optimizing the Marshall properties and taking into account the coating of aggregates, the amount of natural zeolite recommended to use in WMA is between $0.3 \%$ and $0.6 \%$ by weight of the aggregates.

The addition of natural zeolite in recycled asphalt mixtures makes it possible to reduce the manufacturing temperature compared to a conventional HMA up to $30^{\circ} \mathrm{C}$, complying with the Marshall parameters.

Recycled WMA mixtures can be manufactured with the addition of natural zeolite at different temperatures, one maximizing the amount of RAP $\left(30 \%\right.$ RAP at $\left.145^{\circ} \mathrm{C}\right)$, another maximizing the decrease in manufacturing temperature $\left(125^{\circ} \mathrm{C}\right.$ and $\left.10 \% \mathrm{RAP}\right)$, and a mixture where both variables are optimized $\left(135^{\circ} \mathrm{C}\right.$ and $20 \%$ RAP).

Therefore, it is feasible to manufacture WMA with the addition of natural zeolite and WMA with the addition of RAP, according to the Chilean standards for pavements. It is recommended to evaluate mechanical properties such as water sensitivity or rutting to extend the scope of knowledge in the performance of these types of asphalt mixtures. It is also recommended to carry out a study of the costs, reduction of energy consumption, and the emission of gases from this type of asphalt mixtures.

Author Contributions: Conceptualization, E.S.-A., G.V.-V. and A.C.-F.; Funding acquisition, G.V.-V.; Investigation, E.S.-A., G.V.-V. and A.C.-F.; Methodology, E.S.-A., G.V.-V. and A.C.-F.; Writing-original draft, E.S.-A.; Writing-review \& editing, G.V.-V. and A.C.-F. All authors have read and agreed to the published version of the manuscript.

Funding: This research was funded by CONICYT program (a FONDEF IDea Project), grant number ID15I10235.

Conflicts of Interest: The authors declare no conflict of interest.

\section{References}

1. Farooq, M.A.; Mir, M.S. Use of reclaimed asphalt pavement (RAP) in warm mix asphalt (WMA) pavements: A review. Innov. Infrastruct. Solut. 2017, 2, 10. [CrossRef]

2. Woszuk, A.; Franus, W. A Review of the Application of Zeolite Materials in Warm Mix Asphalt Technologies. Appl. Sci. 2017, 7, 293. [CrossRef]

3. Hansen, K.R.; Copeland, A. Asphalt Pavement Industry Survey on Recycled Materials and Warm Mix Asphalt Usage: 2014; Information Series 138; NAPA: Lanham, MD, USA, 2015; p. 28.

4. Sengoz, B.; Topal, A.; Gorkem, C. Evaluation of natural zeolite as warm mix asphalt additive and its comparison with other warm mix additives. Constr. Build. Mater. 2013, 43, 242-252. [CrossRef]

5. Sanchez-Alonso, E.; Vega-Zamanillo, A.; Castro-Fresno, D.; DelRio-Prat, M. Evaluation of compactability and mechanical properties of bituminous mixes with warm additives. Constr. Build. Mater. 2011, 25, 2304-2311. [CrossRef]

6. Sanchez-Alonso, E.; Vega-Zamanillo, A.; Calzada-Perez, M.A.; Castro-Fresno, D. Effect of warm additives on rutting and fatigue behaviour of asphalt mixtures. Constr. Build. Mater. 2013, 47, 240-244. [CrossRef]

7. Woszuk, A.; Franus, W. Properties of the warm mix asphalt involving clinoptilolite and Na-P1 zeolite additives. Constr. Build. Mater. 2016, 114, 556-563. [CrossRef]

8. Topal, A.; Sengoz, B.; Kok, B.V.; Yilmah, M.; Agazadeh Dokhandari, P.; Oner, J.; Kaya, D. Evaluation of mixture characteristics of warm mix asphalt involving natural and synthetic zeolite additives. Constr. Build. Mater. 2014, 57, 38-44. [CrossRef]

9. Wu, S.; Li, X. Evaluation of effect of curing time on mixture performance of Advera warm mix asphalt. Constr. Build. Mater. 2017, 145, 62-67. [CrossRef]

10. Chang, C.-J.; Tseng, L.; Lin, T.-S.; Wang, W.-J.; Lee, T.-C. Recycling of modified MSWI ash-mix slag and CMP sludge as a cement substitute and its optimal composition. Indian J. Eng. Mater. Sci. 2012, 19, 31-40. 
11. Xu, S.; Xiao, F.; Amirkhaniana, S.; Singh, D. Moisture characteristics of mixtures with warm mix asphalt technologies-A review. Constr. Build. Mater. 2017, 142, 148-161. [CrossRef]

12. Sengoz, B.; Topal, A.; Oner, J.; Yilmaz, M.; Aghazadeh Dokandari, P.; Kok, B.V. Performance evaluation of warm mix asphalt mixtures with recycled asphalt pavement. Period. Polytech. Civil. Eng. 2017, 61, 117-127. [CrossRef]

13. Mallick, R.; Kandhal, P.; Bradbury, R. Using warm mix asphalt technology to incorporate high percentage of reclaimed asphalt pavement material in asphalt mixtures. J. Transp. Res. Board 2008, 2051, 71-79. [CrossRef]

14. O'Sullivan, K.; Wall, P. The Effects of Warm Mix Asphalt Additives on Recycled Asphalt Pavement. Bachelor of Science Thesis, Worcester Polytech Inst., Worcester, MA, USA, 2009.

15. Mallick, R.; Bradley, J.; Bradbury, R. Evaluation of heated reclaimed asphalt pavement material and wax-modified asphalt for use in recycled hot-mix asphalt. Transp. Res. Rec. J. Transp. Res. Board 2007, 1998, 112-122. [CrossRef]

16. Xiao, F.; Hou, X.; Amirkhanian, S.; Kim, K.W. Superpave evaluation of higher RAP contents using WMA technologies. Constr. Build. Mater. 2016, 112, 1080-1087. [CrossRef]

17. Zhao, S.; Huang, B.; Shu, X.; Woods, M. Comparative evaluation of warm mix asphalt containing high percentages of reclaimed asphalt pavement. Constr. Build. Mater. 2013, 44, 92-100. [CrossRef]

18. Oner, J.; Sengoz, B. Utilization of Recycled Asphalt Concrete with Warm Mix Asphalt and Cost-Benefit Analysis. PLoS ONE 2015, 10, e116180. [CrossRef] [PubMed]

19. Kandhal, P.S.; Mallick, R.B. Pavement Recycling Guidelines for State and Local Governments; Report No. FHWA-SA-98-042; US Department of Transportation, Federal Highway Administration: Washington, DC, USA, 1997.

20. Don Brock, J.; Richmond, J.L. Technical Paper T-127: Milling and Recycling; ASTEC INC.: Chatanooga, TN, USA, 2007; p. 36.

(C) 2020 by the authors. Licensee MDPI, Basel, Switzerland. This article is an open access article distributed under the terms and conditions of the Creative Commons Attribution (CC BY) license (http://creativecommons.org/licenses/by/4.0/). 